\title{
Dynamic Target Setting increases workplace physical activity: evidence from a randomised trial ${ }^{1}$
}

\author{
Susannah Hume MSc ${ }^{2}$, Pieter Cornel $\mathrm{MSc}^{3}$, Michael Sanders $\mathrm{PhD}^{4}$, Karen Tindall $\mathrm{PhD}^{5}$, \\ Paul Vilanti ${ }^{6}$, Sarah Coghlan ${ }^{7}$, Anna Flego $^{8}$
}

\footnotetext{
${ }^{1}$ We are grateful to the Movember Foundation for funding this research. We are also grateful to Olga Loseva from BUPA UK for making this research possible. We are grateful to seminar participants at the University of Pennsylvania, and participants at the Harvard Behavioural Insights and Public Health conference.

2 The Policy Institute at King's College London, 22 Kingsway, London WC2B 6LE, susannah.hume@kcl.ac.uk

${ }^{3}$ Behavioural Insights Team

${ }^{4}$ King' College London

${ }^{5}$ Behavioural Insights Team

${ }^{6}$ Movember Foundation

${ }^{7}$ Movember Foundation

${ }^{8}$ Movember Foundation
} 


\section{Dynamic Target Setting increases workplace physical activity: evidence from a randomised trial ${ }^{9}$}

Physical activity is an essential part of maintaining a healthy lifestyle. People who are more physically active have healthier weights, less incidence of heart disease and diabetes, and are concurrently less likely to miss work due to ill health ${ }^{1}$.

Physical activity trackers have grown in use as a tool for helping people increase their activity levels. The evidence on the effectiveness of activity tracking devices by themselves is not encouraging, with some studies ${ }^{2}{ }^{3}$ finding either no effects or inclusive results, while some find reductions in weight loss as a consequence ${ }^{4}$. Patel et al (2015), argue convincingly that there is a gulf between measurement and behaviour change that wearable devices are failing to bridge, and that these devices can at best act as facilitators for other interventions ${ }^{5}$.

Many devices provide a default target of 10,000 steps per day - an arbitrary target dating from the $1960 \mathrm{~s}^{6}$. Research suggests that there is benefit to any incremental increase in step counts, and that trying to hit 10,000 steps every day can be demotivating ${ }^{7}$ and reduce the enjoyment derived from walking ${ }^{8}$. Goals tailored to the individual based on their past performance might more effectively motivate behaviour than a single 'one size fits all' target. We test this hypothesis.

The experiment was conducted with a large private firm based in the United Kingdom. Participants were employees of the company, who had signed up to the company's internal health and wellbeing app, and who had registered a wearable or phone-based activity tracker on the app, had recorded at least some steps in the week before the trial began, and consented to be part of the study. This gives a sample of 387 individuals, who were individually randomized to one of two conditions.

Participants received an introductory push notification from a 'Coach', and then one message each week for four weeks, with the content dictated by their treatment condition.

Standardised target condition: Participants received weekly push notifications from the Coach including a standard 10,000 step goal for the subsequent week.

Dynamic Personalised Target condition: Participants in the personalised target condition received weekly push notifications from the Coach, with targets based on their step count for the previous week. If they had met their step count for the previous week, their target increased by $10 \%$; if they had not, it remained the same.

\footnotetext{
${ }^{9}$ We are grateful to the Movember Foundation for funding this research. We are also grateful to Olga Loseva from BUPA UK for making this research possible. We are grateful to seminar participants at the University of Pennsylvania, and participants at the Harvard Behavioural Insights and Public Health conference.
} 
Data on participants' steps were collected from the company's health and wellbeing app at the end of each week, and used to tailor the message in the personal target condition, as well as being collated for analysis.

The sample for the experiment consists of 387 individuals, of whom 199 are female, 178 are male, and 10 did not provide information on their gender.

Our data are analysed using panel regression with participant fixed effects to control for baseline activity (Table 1$)$. We see a positive and statistically significant $(p<0.001) 1202$ steps per day increase in the treatment group compared to the control group. This is driven in part by participants becoming more likely to use their wearable during the trial. Excluding those participants, we see a smaller increase, of 788 steps per participant per day, which remains statistically significant $(p<0.05)$.

We are also interested in the distribution of the effects. We conduct quantile regressions at the 25th, 75th percentiles and median. We find consistently positive and significant effects at each point, but that the size of treatment effects increases in line with the dynamic targets.

These findings suggest a role for dynamic target setting in increasing the effectiveness of wearable devices at increasing physical activity, with relevance for both employers and those wishing to increase their own activity.

Table 1 Main Results

(1)

(2)

\begin{tabular}{lcc|}
\cline { 2 - 3 } & Full Sample & Active Sample \\
\cline { 2 - 3 } $\begin{array}{l}\text { Sample, Level of } \\
\text { Analysis }\end{array}$ & $\begin{array}{c}\text { (Full sample, day } \\
\text { level) }\end{array}$ & $\begin{array}{c}\text { ("Clean” sample, day } \\
\text { level) }\end{array}$ \\
\hline Treatment & $1202.443^{* * *}$ & $788.580^{*}$ \\
& $(200.388)$ & $(347.375)$ \\
Constant & $3619.552^{* * *}$ & $4888.944^{* * *}$ \\
& $(333.443)$ & $(230.058)$ \\
\hline$N$ & 13932 & 6230 \\
\hline $\begin{array}{c}* \\
p<0.05,{ }^{* *} p<0.01,{ }^{* * *} p<0.001, \text { fixed effects panel regression estimates with standard errors clustered at the } \\
\text { level of the participant. }\end{array}$
\end{tabular}


Table 2: Quantile Regressions of Treatment Effects

(1)

(25th Percentile)
(2)

(Median)

$827.000^{* * *}$

$(213.802)$

(203.925)

$4188.000^{* * *}$

$7233.000^{* * *}$

$(307.283)$

(293.087)
(3)

(75th Percentile)

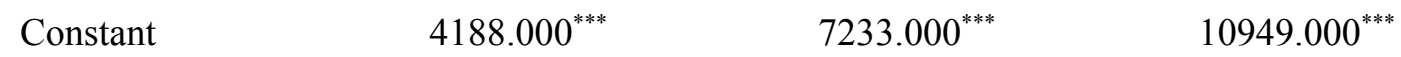
6094

$(362.818)$

\begin{tabular}{l}
\hline$N 6094 \quad 6094$ \\
\hline${ }^{*} p<0.05,{ }^{* *} p<0.01,{ }^{* * *} p<0.001$, quantile regressions presented at the 25 th percentile, median and 75 th \\
percentile. Standard errors clustered at the level of the participant.
\end{tabular}

\section{References}

1. Reiner M, Niermann $C$, Jekauc $D$, Woll A. Long-term health benefits of physical activity-a systematic review of longitudinal studies. BMC public health. 2013; 13(1):1-9.

2. Shuger SL, Barry VW, Sui X, et al. Electronic feedback in a diet-and physical activity-based lifestyle intervention for weight loss: a randomized controlled trial. International Journal of Behavioral Nutrition and Physical Activity. 2011; 1;8(1):41.

3. Harris T, Kerry SM, Victor CR, et al. A primary care nurse-delivered walking intervention in older adults: PACE (pedometer accelerometer consultation evaluation)-Lift cluster randomised controlled trial. PLoS Med. 2015; 17;12(2):e1001783.

4. Jakicic JM, Davis KK, Rogers RJ, et al. Effect of wearable technology combined with a lifestyle intervention on long-term weight loss: the IDEA randomized clinical trial. JAMA. 2016;

20;316(11):1161-71.

5. Patel MS, Asch DA, Volpp KG. Wearable devices as facilitators, not drivers, of health behavior change. JAMA. 2015; 3;313(5):459-60.

6. Tudor-Locke, C., \& Bassett, D. R. (2004). How many steps/day are enough?. Sports medicine, 34(1), 1-8.

7. Kerner, C., \& Goodyear, V. A. (2017). The motivational impact of wearable healthy lifestyle technologies: a self-determination perspective on Fitbits with adolescents. American Journal of Health Education.

8. Etkin, J. (2016). The hidden cost of personal quantification. Journal of Consumer Research, 42(6), 967-984. 